\title{
ANALISA KINERJA QUERY STORED PROCEDURE PADA DATABASE MANAGEMENT SYSTEM (DBMS) MYSQL
}

\author{
Indra Warman ${ }^{1)}$, Wildani ${ }^{2)}$ \\ Fakultas Teknik, Institut Teknologi Padang \\ E-mail: indrawmn@gmail.com,Wildani1000@gmail.com
}

\begin{abstract}
Abstrak
Abstrak : Penggunaan query pada database dengan jumlah record data transaksi yang besar tentunya membutuhkan akses sumber daya DBMS (Database management System), pada database MySQL, query yang digunakan untuk jumlah record data ribuan tentunya akan mempengaruhi kinerja database, eksekusi $S Q L$ query dengan jumlah record yang sangat banyak akan memerlukan waktu yang lama dan mempengaruhi waktu proses pengolahan data. Penggunaan perintah SQL stored procedure dapat mengoptimalkan penggunaan query terutama untuk melakukan perintah yang sering digunakan dalam manipulasi data, sehingga akan mempercepat proses, stored procedure merupakan kumpulan pernyataan Query yang disimpan pada database, untuk itu perlu dilakukan pengujian kinerja waktu eksekusi query. Penelitian ini bertujuan memberikan analisis kinerja query stored procedure pada Relational Database Management System (RDBMS) MySQL. Pada penelitian dilakukan pengujian kinerja query stored procedure dengan jumlah record data dari 50 sampai dengan 25000. Query stored procedure yang diuji menggunakan perintah SQL (Create, Select, Update, Delete) dengan kasus database transaksi belanja online. Hasil rekapitulasi pengujian kinerja query stored procedure pada MySQL menunjukkan pada pengujian query stored procedure select dan delete waktu eksekusinya berbanding lurus dengan jumlah record datanya. Sedangkan pengujian query stored procedure create dan update terjadi peningkatan waktu eksekusi yang cukup signifikan terutama pengujian dengan jumlah 25000 record data.
\end{abstract}

Kata Kunci: SQL Query, Stored Procedure, MySQL, Kinerja, RDBMS

Abstract : The Utilization of queries on databases with a large number of transaction data records will make requires access to DBMS (Database management System) resources, in MySQL databases, queries used for the number of data records in the thousands will certainly affect the performance of the database. SQL query execution with a very large number of records will take a long time and will affect the data processing time. The use of SQL stored procedure can optimize the use of queries, especially for SQL that are often used in data manipulation, so that it will speed up the process, stored procedures are a collection of query statements that are created and then stored in the database and can be reused. execution in query stored procedure. This study aims to provide a performance analysis of the query stored procedure in the MySQL Relational Database Management System (RDBMS). In this research, the performance of the query stored procedure was tested with the number of data records from 50 to 25000. The query stored procedure being tested is using the SQL command (Create, Select, Update, Delete) with the transaction database case of on online shopping. The recapitulation of performance testing for stored procedure queries in MySQL shows that in testing the stored procedure, select and delete execution time is directly proportional to the number of data records. Meanwhile, testing of query stored procedure create and update has a significant increase in execution time, especially in testing with a total of 25000 data records.

Keywords: SQL Query, Stored Procedure, Mysql, Performance, RDBMS

\section{PENDAHULUAN}

Penggunaan Teknologi Database

terutama Relational Database

Management System (RDBMS) yang

berisi data-data yang terstruktur, dimana antara satu table dengan table yang lainnya dihubungkan dengan kunci relasi (Kadir, 2020). Berdasarkan $d b$-engine ranking Mei tahun 2020 RDBMS MySQL merupakan urutan kedua RDBMS terpopuler dan 
banyak digunakan (https://db-engines.com, 2020). Database Mysql mendukung untuk aspek keamanan dan penggunaan stored procedure (Solichin, 2010). Pada database MySQL, query SQL yang digunakan untuk jumlah record data dengan jumlah ribuan tentunya akan mempengaruhi kinerja database (Muliyantoro, 2013). eksekusi SQL query dengan jumlah record yang sangat banyak akan memerlukan waktu yang lama dan akan mempengaruhi waktu proses pengolahan data (Hastono, 2019a). Untuk mengoptimalkan query dengan record data yang sangat banyak dapat dilakukan dengan optimasi dengan menggunakan stored procedure (Hastono, 2019b).

Penggunaan stored procedure memiliki beberapa manfaat diantaranya : lebih sedikit hasil duplikasi, eksekusi lebih cepat, lalu lintas jaringan minimum dan keamanan yang lebih baik. Stored procedure ini dapat digunakan untuk membagi beban resource yang terpakai pada saat aplikasi yang sedang berjalan. Stored procedure juga efektif digunakan untuk eksekusi query yang dilakukan secara rutin dan diproses pada database server sehingga dapat memangkas waktu eksekusi dan akan mempercepat proses pada kerja dari pengolahan data, Selain meringkas penggunaan sintak query SQL juga dapat meningkatkan performasi dari database. Sehingga lebih mudah menentukan penerapan database terhadap pengguna dalam menggunakan stored procedure.

Berdasarkan hal tersebut maka diperlukan suatu analisa untuk melihat kinerja query stored procedure pada DBMS MySQL. Tujuan dari penelitian ini adalah untuk memberikan analisis kinerja query stored procedure pada Relational Database Management System (RDBMS) MySQL menggunakan eksekusi dari perintah SQL (Create/Insert, Select, Update, Delete).

\section{METODE PENELITIAN}

Penelitian ini merupakan suatu metode analisa, yaitu analisa kinerja query stored procedure pada Database Management System (DBMS) MySQL. Penelitian ini dilakukan agar dapat melihat kinerja query stored procedure terhadap Database Management System (DBMS) MySQL. Database MySQL yang digunakan pada penelitian ini adalah MySQL 5.6.21 Community, rancangan pengujian kinerja query stored procedure pada DBMS MySQL ini, dilakukan perintah SQL (Create/Insert, Select, Update, Delete) dengan jumlah record data mulai dari 50, 100, 500, 1000, 5000, 10000, sampai 25000 pada DBMS MySQL sehingga waktu eksekusi perintah query tersebut dapat dianalisa, pengukuran kinerja pada variabel (Stored Procedure) menggunakan query melalui MySQL Command line, hal ini dilakukan untuk validates waktu pengukuran, dibandingkan dengan menggunakan tools melalui browser yang nantinya akan dipengaruhi oleh cache pada browser tersebut.

Tahapan yang dilakukan dalam penelitian adalah instalasi dan konfigurasi database MySQL pada OS Windows 10 64bit, merancang struktur table pada database yang akan digunakan sebagai pengujian query, eksekusi query stored procedure (Create/Insert, Select, Update, Delete) dilakukan secara bertahap dengan jumlah record data yang berbeda.

\section{HASIL DAN PEMBAHASAN Pengujian Kinerja Query Pada DBMS MySQL}

Pada rancangan pengujian kinerja query stored procedure pada DBMS MySQL nantinya dilakukan perintah SQL (Create, Select, Update, Delete) dengan jumlah record data mulai dari 50, 100, 500, 1000, 5000, 10000, sampai 25000, selanjutnya akan terlihat selisih waktu eksekusi pengujian query stored 
procedure, sehingga kecepatan pada masing-masing query yang diujikan dapat dianalisa.

Query create/insert ini menggunakan perintah SQL insert untuk melakukan penambah data pada table orderan. Berikut ini adalah contoh penggunaan query dengan stored procedure dengan perintah create/insert pada table orderan.

delimiter //

create procedure insert_orderan25000(

te int,

id_pel varchar(8),

id_pro varchar(5),

ha int,

jum int,

dis float,

t_ba int,

tgl_pe date,

id_k int)

begin

insert into

orderan(trx,id_pelanggan,id_produk,harga,ju

mlah,diskon,total_bayar,tgl_pesan,id_ket)

values(te,id_pel,id_pro,ha,jum,dis,t_ba,tgl_p

e,id_k);

end;

//

call insert_orderan25000 (25001,'p0009', 'd0017', 125000, 1, 0, 125000, '2021-01-10', $1)$;

\section{Stored Procedure create/insert data}

Hasil pengujian perintah SQL stored procedure insert data mulai dari 50 sampai dengan 25.000 record sample data yang dilakukan, selanjutnya dilakukan direkapitulasi pada tabel.1, untuk menampilkan hasil waktu pengujian proses query SQL stored procedure insert.

Tabel 1. Hasil Store Procedure create/insert

\begin{tabular}{c|c|c|c|c|c|c|c|}
\hline $\begin{array}{c}\text { Keterangan } \\
\text { (Jumlah Record } \\
\text { Data) }\end{array}$ & $\mathbf{5 0}$ & $\mathbf{1 0 0}$ & $\mathbf{5 0 0}$ & $\mathbf{1 0 0 0}$ & $\mathbf{5 0 0 0}$ & $\mathbf{1 0 0 0 0}$ & $\mathbf{2 5 0 0 0}$ \\
\hline $\begin{array}{c}\text { Waktu Eksekusi } \\
\text { (Sec) }\end{array}$ & 0,09 & 0,12 & 0,10 & 0,10 & 0,12 & 0,20 & 0,23 \\
\hline
\end{tabular}

\section{Stored Procedure create/insert data (grafik)}

Untuk menampilkan hasil pengujian pada tabel.1, berikut adalah informasi dalam bentuk grafik yang terkait SQL store procedured insert data yang dilakukan pada table mulai dari 50 sampai dengan 25.000 record, pada gambar 1 . menampilkan rekapitulasi pengujian data serta waktu proses query SQL stored procedure insert, seperti berikut :

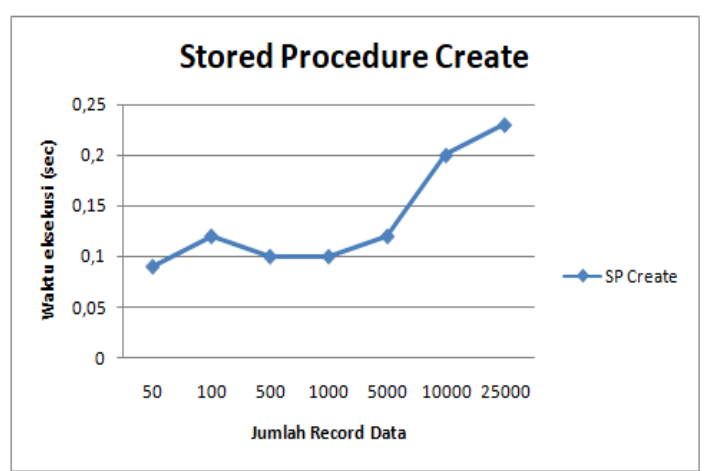

Gambar 1. Grafik Hasil Query Stored Procedure Create/insert data

1. Query Stored Procedure Select

Query stored procedure dengan perintah select digunakan untuk melihat menyeleksi, atau memilih data pada tabel-tabel yang ada dalam database. Query select ini bisa menampilkan semua kolom, sebagian kolom, serta berdasarkan kondisi yang diinginkan, berikut adalah contoh penggunaan query dengan stored procedure dengan perintah select pada tabe; dalam database:

delimiter //

create procedure tampil()

begin

Select

pelanggan.nm_pelanggan,produk.nm_pro duk,orderan.jumlah,orderan.total_bayar

from

pelanggan,produk,orderan

where

pelanggan.id_pelanggan=orderan.id_pela nggan and

produk.id_produk=orderan.id_produk and id_ket=2;

end;

//

Call tampil ();

\section{Stored Procedure Select}

Hasil pengujian perintah SQL store procedure select yang dilakukan mulai 
dari 50 sampai dengan 25.000 record sample data, selanjutnya dilakukan rekapitulasi untuk menampilkan waktu pengujian proses query SQL stored procedure select, seperti pada tabel 2 berikut :

Tabel 2. Hasil Pengujian Select

\begin{tabular}{|c|c|c|c|c|c|c|c|}
\hline $\begin{array}{c}\text { Keterangan } \\
\text { (Jumlah } \\
\text { Record Data) }\end{array}$ & $\mathbf{5 0}$ & $\mathbf{1 0 0}$ & $\mathbf{5 0 0}$ & $\mathbf{1 0 0 0}$ & $\mathbf{5 0 0 0}$ & $\mathbf{1 0 0 0 0}$ & $\mathbf{2 5 0 0 0}$ \\
\hline $\begin{array}{c}\text { Waktu } \\
\text { Eksekusi } \\
\text { (Sec) }\end{array}$ & 0,53 & 0,93 & 3,70 & 6,64 & 31,50 & 47,20 & 152,28 \\
\hline
\end{tabular}

\section{Stored Procedure select (grafik)}

Untuk menampilkan hasil pengujian pada tabel.2, berikut merupakan informasi dalam bentuk grafik yang terkait SQL stored procedure select record data yang dilakukan pada table mulai dari 50 sampai dengan 25.000 record, pada gambar 2 . menampilkan rekapitulasi hasil pengujian data serta waktu proses query SQL stored procedure select.

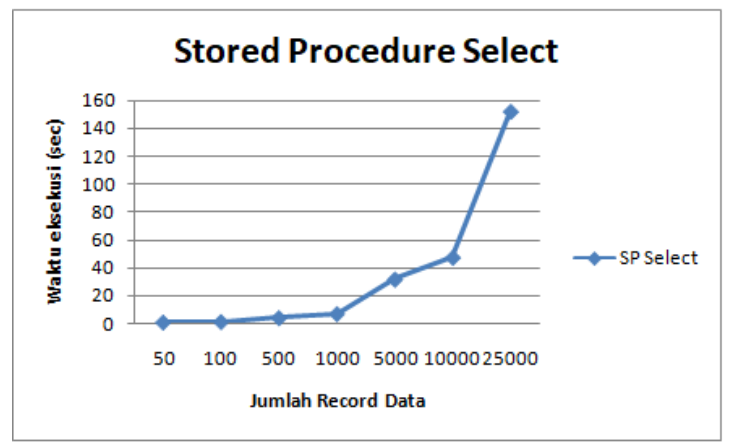

Gambar 2. Grafik Hasil Query Stored Procedure Select

\section{Query Stored Procedure Update}

Query stored procedure dengan perintah update berguna untuk mengubah data pada database, berikut adalah contoh penggunaan query dengan stored procedure dengan perintah update dalam database.

delimiter //

create procedure updatedata50()

begin

update orderan50 set id_ket=3

where

id_ket $=2$;

end;
//

call updatedata50();

\section{Stored Procedure update}

Hasil pengujian perintah SQL stored procedure update record data mulai dari 50 sampai dengan 25.000 record sample data yang dilakukan, selanjutnya dilakukan direkapitulasi pada tabel 3, untuk menampilkan hasil waktu pengujian proses query SQL stored procedure create yang dibutuhkan, seperti berikut :

Tabel 3. Hasil Pengujian Update

\begin{tabular}{|c|c|c|c|c|c|c|c|}
\hline $\begin{array}{c}\text { Keterangan } \\
\text { (Jumlah } \\
\text { Record Data) }\end{array}$ & $\mathbf{5 0}$ & $\mathbf{1 0 0}$ & $\mathbf{5 0 0}$ & $\mathbf{1 0 0 0}$ & $\mathbf{5 0 0 0}$ & $\mathbf{1 0 0 0 0}$ & $\mathbf{2 5 0 0 0}$ \\
\hline $\begin{array}{c}\text { Waktu } \\
\text { Eksekusi } \\
\text { (Sec) }\end{array}$ & 0,11 & 0,13 & 0,31 & 0,43 & 0,50 & 0,50 & 1,16 \\
\hline
\end{tabular}

\section{Stored Procedure update (grafik)}

Untuk menampilkan hasil pengujian pada tabel.3, berikut merupakan informasi dalam bentuk grafik terkait SQL stored procedure update record data yang dilakukan pada table mulai dari 50 sampai dengan 25.000 record data, pada gambar 3 menampilkan rekapitulasi hasil pengujian data serta waktu proses yang dibutuhkan query SQL stored procedure update.

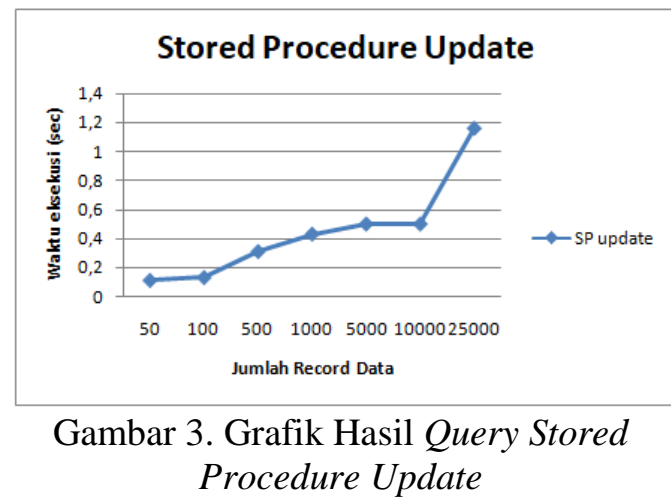

Query stored procedure dengan perintah delete berguna untuk menghapus data pada database. Berikut ini adalah contoh penggunaan query dengan stored procedure dengan perintah delete dalam database:

delimiter // create procedure deletedata50() begin delete from orderan50 
where id_ket=3;

end;

//

call deletedata50();

\section{Stored Procedure delete}

Pada pengujian perintah SQL stored procedure delete record data mulai dari 50 sampai dengan 25.000 record sample data yang dilakukan, selanjutnya hasil query dilakukan direkapitulasi pada tabel 4, untuk menampilkan hasil waktu pengujian proses query SQL stored procedure delete, seperti berikut :

Tabel 4. Hasil Pengujian Delete

\begin{tabular}{|c|c|c|c|c|c|c|c|}
\hline $\begin{array}{c}\text { Keterangan } \\
\text { (Jumlah } \\
\text { Record Data) }\end{array}$ & $\mathbf{5 0}$ & 100 & $\mathbf{5 0 0}$ & $\mathbf{1 0 0 0}$ & $\mathbf{5 0 0 0}$ & $\mathbf{1 0 0 0 0}$ & $\mathbf{2 5 0 0 0}$ \\
\hline $\begin{array}{c}\text { Waktu } \\
\text { Eksekusi } \\
\text { (Sec) }\end{array}$ & 0,10 & 0,13 & 0,26 & 0,28 & 0,32 & 0,40 & 0,96 \\
\hline
\end{tabular}

\section{Stored Procedure delete (grafik)}

Untuk menampilkan hasil pengujian pada tabel.4, berikut merupakan informasi dalam bentuk grafik yang terkait SQL store procedure delete record data pada table mulai dari 50 sampai dengan 25.000 record data, pada gambar 4. menampilkan rekapitulasi hasil pengujian data serta waktu proses query SQL stored procedure delete.

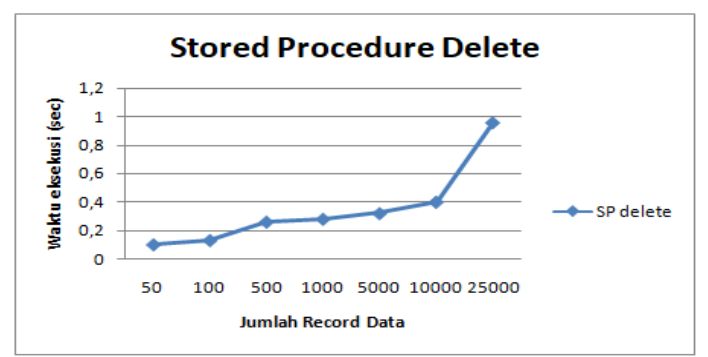

Gambar 4. Grafik Hasil Query Stored

Procedure Delete

\section{Rekapitulasi SQL Stored Procedure}

Pada rekapitulasi query berikut merupakan hasil pengujian store procedure ( create/insert, select, update, delete) pada table 1 sampai dengan tabel 4 , seperti terlihat pada tabel.5 berikut ini :
Tabel 5. Rekapitulasi Query Stored Procedure

\begin{tabular}{|c|c|c|c|c|}
\hline \multirow{2}{*}{$\begin{array}{c}\text { Jumlah } \\
\text { record } \\
\text { Data }\end{array}$} & \multicolumn{4}{|c|}{ Waktu Eksekusi Stored Procedure } \\
\hline & Create & Select & Update & Delete \\
\hline 50 & 0,09 & 0,53 & 0,11 & 0,10 \\
\hline 100 & 0,12 & 0,93 & 0,13 & 0,13 \\
\hline 500 & 0,10 & 3,70 & 0,31 & 0,26 \\
\hline 1000 & 0,10 & 6,64 & 0,43 & 0,28 \\
\hline 5000 & 0,12 & 31,50 & 0,50 & 0,32 \\
\hline 10000 & 0,20 & 47,20 & 0,50 & 0,40 \\
\hline 25000 & 0,23 & 152,28 & 1,16 & 0,96 \\
\hline
\end{tabular}

\section{Rekapitulasi SQL Stored Procedure}

Rekapitulasi hasil pengujian pada masingmasing store procedure ( create/insert, select, update, delete) pada pada tabel 1 sampai dengan 4, ditampilkan dalam bentuk grafik seperti gambar 5. Hasil pengujian stored procedure dengan perintah select pada record data 500 sampai 25000 waktu eksekusinya sangat meningkat, waktu eksekusi meningkat secara signifikan pada pada record data 5000, 10000, dan 25000 dengan waktu eksekusi 31,50 sec, 47,20 sec, dan 152,28 sec. Pengujian stored procedure menggunakan perintah create/insert data waktu eksekusinya bervariasi dimana perbandingam waktu eksekusinya kecil, waktu eksekusi terbesar yang digunakan 0,23 sec pada record data 25000 . Selanjutnya pengujian stored procedure menggunakan perintah update waktu eksekusinya bervariasi. Pada record data 5000 dan 10000 memerlukan waktu eksekusi yang sama $0,50 \mathrm{sec}$, untuk waktu eksekusi terlama pada pengujian record data 25000 yaitu $1,16 \mathrm{sec}$, sedangkan pengujian stored procedure menggunakan perintah delete waktu eksekusinya mengalami peningkatan setiap melakukan pengujian dengan penambahan record data, waktu eksekusi naik secara signifikan pada record data 5000, 10000, dan 25000 dengan waktu eksekusi $0,32 \mathrm{sec}, 0,40 \mathrm{sec}$, dan $0,96 \mathrm{sec}$. 


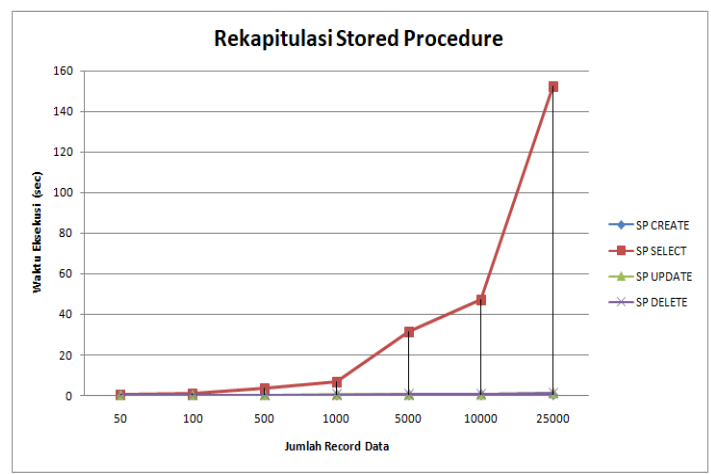

Gambar 5. Grafik Rekapitulasi Stored Procedure

\section{KESIMPULAN}

Berdasarkan hasil rekapitulasi pengujian kinerja query stored procedure pada MySQL menunjukkan bahwa pada pengujian query stored procedure select dan delete waktu eksekusi berbanding lurus dengan jumlah record datanya, sedangkan pengujian query stored procedure create dan update terjadi peningkatan waktu eksekusi yang cukup signifikan terutama pada pengujian dengan jumlah 25000 record data.

\section{DAFTAR PUSTAKA}

Dudu, A. et al. 'Pengukuran Kinerja Stored Procedure Pada Database Relasional ',Jurnal Siliwangi Sains Teknologi, 5(2), 2019, pp. 51-55.

Hastono, T. 'Optimasi Query Sistem Informasi Menggunakan Stored Procedure', Jurnal Dinamika Informatika , 8(2), 2019a, pp. 79-89.

Hastono, T. 'Query pada Sistem Informasi Keuangan SD Muhhamadiyah Sidoarum Berbasis Client-Server', 2019b, pp. 35-39.

https://db-engines.com The DB-Engines Ranking ranks database management systems according to their popularity. The ranking is updated monthly., https://db-engines.com. Available at: https://db-engines.com/en/ranking,
2020.

Kadir, A. Dasar Perancangan dan Implementasi Database Relasional (Edisi Revisi). Penerbit Andi, 2020

Muliyantoro, H. S. (2013) 'Penerapan Metode Load-Balancing Clusters Pada Database Server Guna Peningkatan Kinerja Pengaksesan Data', Jurnal Techno Nusa Mandiri, 10(1), pp. 97108.

Solichin, A. MySQL5: Dari Pemula Hingga Mahir. Achmad Solichin. 2010 